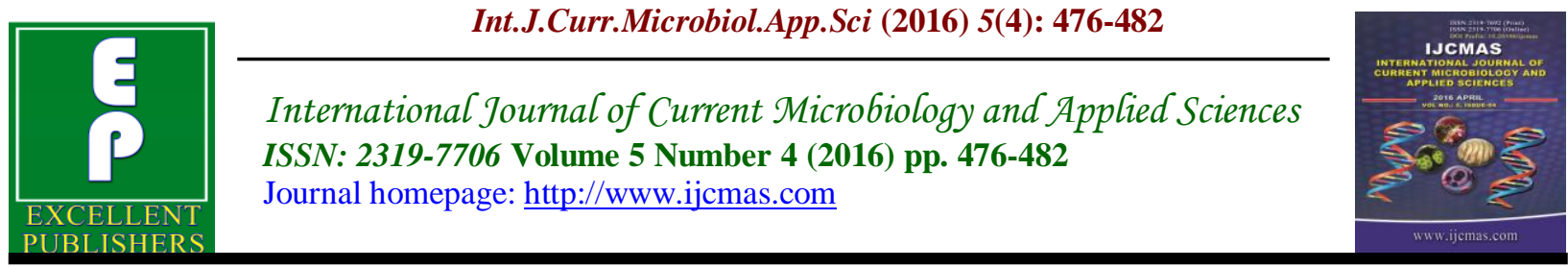

Original Research Article

http://dx.doi.org/10.20546/ijcmas.2016.504.056

\title{
Analysis of Phyto-Constituents and Free Radical Neutralizing activity of Cassia alata-A Green Source for Ag Np's Synthesis
}

\author{
K. Kavipriya and M. Chandran* \\ Department of Zoology, Thiruvalluvar University, Vellore, India \\ *Corresponding author
}

Keywords

Antioxidant activity,

Cassia alata, Phytocomponents,

Silver nanoparticles.

Article Info

Accepted:

16 March 2016

Available Online:

10 April 2016

\author{
A B S T R A C T
}

Cassia alata is a lesser exploited plant for its biological activity due to its greater ornamental value which always cover medicinal applications. In the present study, Nanoparticle fabrication ability of the leaf extract was exploited for the successful synthesis of silver nanoparticles. It was observed that the extract could mediate the synthesis nanoparticle in lesser time with a high synthesis rate. Major phytocomponents present in the extract was analyzed and high percentage of phenolic compounds were observed, however there were traces of tannins, saponins etc. phytocompounds were found to facilitate free radical scavenging ability of the extract. From the analyzed parameters such as $\mathrm{H}_{2} \mathrm{O}_{2}$ scavenging activity, super oxide radical scavenging, lipid peroxidation inhibition activity and DPPH assay, it was evident that extract possess high degree of antioxidant capacity, which was found to be proportional to its concentration.

\section{Introduction}

Since prehistoric time, medicinal plants have been exploited for their antimicrobial, antimalarial and analgesic activity (Chatterjee et al., 2012). Studies conducted so for upon medicinal plants can be categorized into two: such as optimization of ancient knowledge about a plant and discovering novel applications of lesser known plants. Both this branches have their own importance, as former enlighten the scientific reason behind ancient medications and the later opens up new possibilities of phyto pharmacology. Interest upon plant based therapeutic agents have been increased now a days after observing their prominent biocompatibility and lesser toxicity than chemically synthesized counterparts (Meenupriya et al., 2014).This trend make research on medicinal plants and their derived compounds of great economic value.

Till date, numerous methods have been explored so far to synthesize nanoparticles such as reduction of solutions, chemical and photochemical reactions, thermal decomposition compounds, radiation assisted, electrochemical, sonochemical and microwave-assisted processes. Plant assisted fabrication of nanomaterials has 
acclimatized for their vast applications, cost effectiveness and biocompatibility (Hasan, 2015). Silver nanoparticle is one among the most desired metal nanoparticle with maximum applications. They are comparatively cheap to synthesize and biological activity of silver enhance the activity of synthesized nanoparticles. Many plants such as Thulsi, Neem (Banerjee et al., 2014), Tomato (Many et al., 2014) and Garlic (White et al., 2012) have been used for the synthesis silver nanoparticle successfully but the demand of improvisation urges to find out more methods and cost effective sources for the same.

Normally nanoparticles are used for binding and transporting drug molecule to their target site due to which ligand receptor interaction will be enhanced and which reduces the required amount of drugs. Hinge on the previous studies, it is assumed that if the carrier nanoparticles can be synthesized by the same plant that with desired activity that will increase the efficacy of drug-carrier conjugate. Cassia alata belongs to the family Caesalpiniaceaeis, widely distributed in tropical countries such as India, Brazil, Indonesia and Fiji. It is commonly called as "Candle Bush Plant" (Ogunwande et al., 2010).

They are well known for their skin protective ability, it is also used against anemia, constipation, dermatitis, dyspepsia, fevers, liver problems, menstrual disorders, and as purgative, expectorant astringent, vermicide (Mohideen et al., 2005). In the present study, the ability of Cassia alata to mediate the synthesis of silver nanoparticle was evaluated and to scrutinize its phytoconstituents and free radical scavenging activity. This enables to develop a drug-nanoparticle conjugate that with antioxidant property.

\section{Materials and MethodS}

\section{Preparation of Plant Extract}

Cassia alata plants were collected from in and around Ranipet, Tamilnadu, India. Plants were identified and verified by authorized botanist and stored for further studies. Five gram of chopped leaf sample was dispersed in $50 \%$ methanol to retrieve extract. It was the kept in a water bath at the temperature of $50^{\circ} \mathrm{C}-60^{\circ} \mathrm{C}$ for $5-6 \mathrm{hrs}$. After cooling, the mixture in the flask was allowed to pass through Whatman filter paper no. 1 and filtrate was collected. Filtrate was vaporized to get a film of plant residue. The extract was stored in screwed tubes in $-4{ }^{0} \mathrm{C}$ to prevent the loss of bioactive compounds until further use (Bhat et al., 2016).

\section{Screening the Ability to Synthesis Ag NP's}

Leaf extract of Cassia alata was used as a source for the synthesis of silver nanoparticles. To $5 \mathrm{ml}$ filtrate, $10 \mathrm{ml}$ of $0.025 \mathrm{M}$ AgNO3 was added and the arrangement was left at room temperature, until the color of the solution changes from light yellow to brown. The presence of $\mathrm{Ag}$ NPs in the solution will be confirmed by a dark brown color (Gaddam et al., 2014).

\section{Phytoconstituent Analysis of Cassia alata}

The presence of alkaloids, phenol, flavonoids, saponins, cardiac glycosides and tannins were analysed by the method described by Mahmood and Doughari (2008). Anthraquinones, steroids and terpenoids were analysed by modifying the methods described by Senthilkumar et al. (2013). Quantitative analysis of Alkaloids, Phenols, Flavanoids and proanthocyanidins were also analysed (Mir et al., 2013). 
Free Radical Scavenging Activity of Extract

Ability of the bioactive compounds to neutralize free radicals were analysed by DPPH assay, super oxide scavenging, inhibition of lipid per oxidation and hydrogen peroxide neutralization assay. DPPH assay was carried out by following the method proposed by Aksoy et al. (2013). Ability of the extract to inhibit lipid peroxidation was determined by the method of Ćetković et al. (2007). Super oxide freeradical scavenging assay (Hazara et al., 2008) and finally hydrogen peroxide assay (Geetha et al., 2013) were also carried out understand the antioxidant ability of methanolic extracts of Cassia alata .

\section{Results and Discussion}

\section{Extraction of Bioactive Compounds}

A significant yield was obtained by methanolic extraction of Cassia alata leaves. Similar extraction was done by Sherikar and Mahanthesh (2015). Elevated yield might be due to the polarity property of methanol (Parekh et al., 2005).

\section{Biofabrication of Silver Nanoparticles by Leaf Extracts}

Leaf extracts of Cassia alata could successfully mediate the synthesis of silver nanoparticle by reducing AgNO3. Change of color from light yellow (which is characteristic color of methanolic extract of Cassia alata) to dark brown proved the reduction and presence of silver nanoparticle. This pattern of color change has been previously reported in nanoparticle synthesis mediated by Solanum nigrum and Clitoria ternatea (Krithiga et al., 2015). The reduction of silver is assumed to be mediated by phytocomponents (Ahmed et al., 2016) that in turn could be mediated either by a single compound or by a group of compounds present in extract.

\section{Phytoconstituent Analysis of the Extract}

This study revealed that the methanolic extract of Cassia alata contained numerous phytochemicals such as alkaloids, flavonoids, saponins, tannins, steroids, cardiac glycosides, terpenoids etc (Table 1). Major component was found to be alkaloids followed by flavonoids. It is assumed that the medicinal properties of a plant are attributed by the phyto constituents present in it. Terpenoids purified from Rhizoma Curcumae have been reported for their anticancer activity (Lu et al., 2012). Alkaloids have been studied for their effect on central nervous system (Patel et al., 2012), whereas flavonoids are used for free radical scavenging (Meng et al., 2012).

Table.1 Phytochemical Composition of Methanolic Extract of Cassia alata

\begin{tabular}{|l|l|l|}
\hline S.No & Phytocomponents & Result \\
\hline 01. & Alkaloids & Positive \\
\hline 02. & Phenol & Positive \\
\hline 03. & Flavonoids & Positive \\
\hline 04. & Saponins & Positive \\
\hline 05. & Cardiac glycosides & Positive \\
\hline 06. & Anthraquinones & Positive \\
\hline 07. & Terpenoids & Positive \\
\hline 08. & Steroids & Positive \\
\hline
\end{tabular}


Fig.1 Hydroxyl Radical Scavenging Activity of Cassia alata

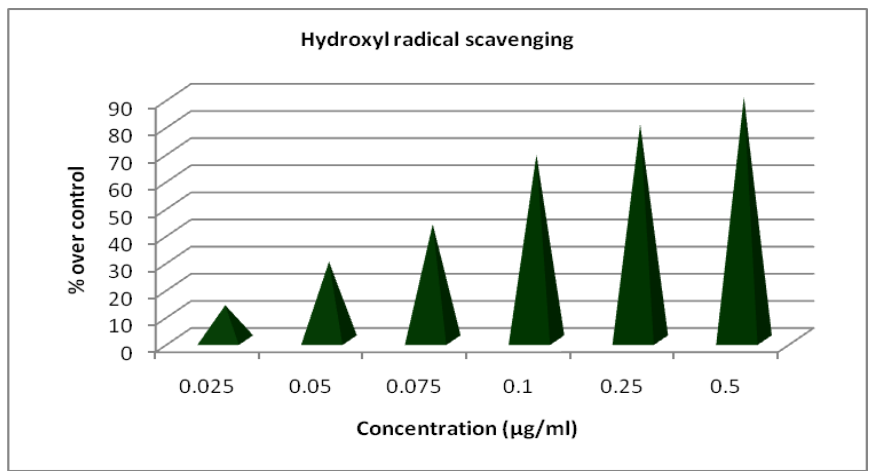

Fig.2 Super Oxide Free Radical Scavenging Activity of Cassia alata

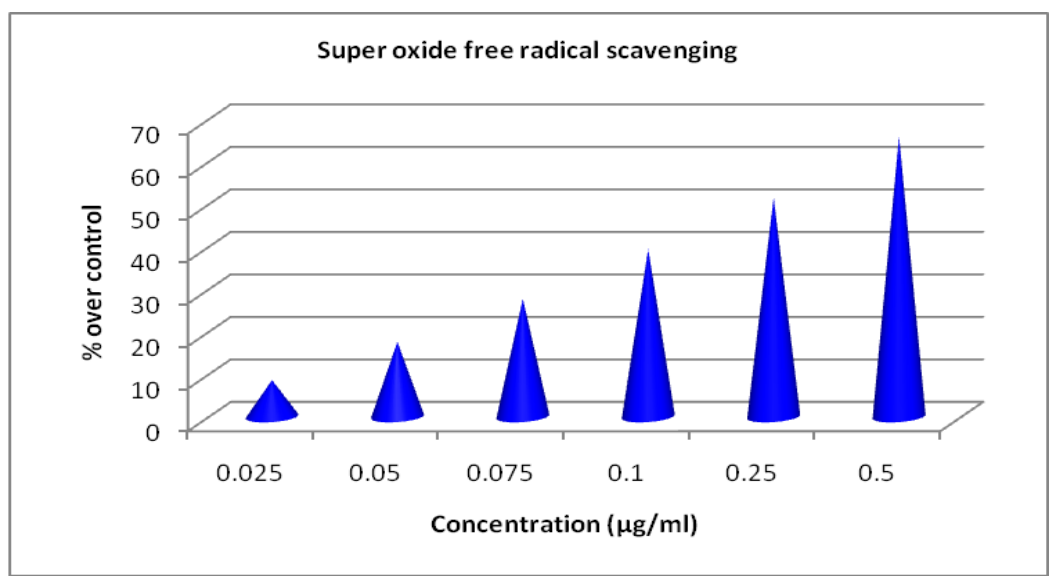

Fig.3 Lipid Peroxidation Inhibition Activity of Cassia alata

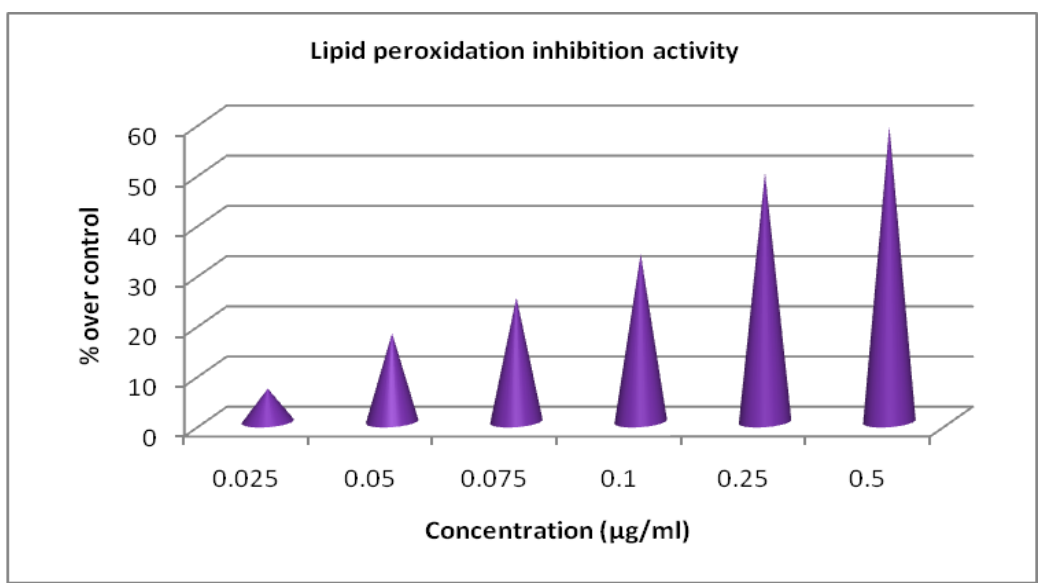


Fig.4 DPPH Assay of Cassia alata's Leaf Extract

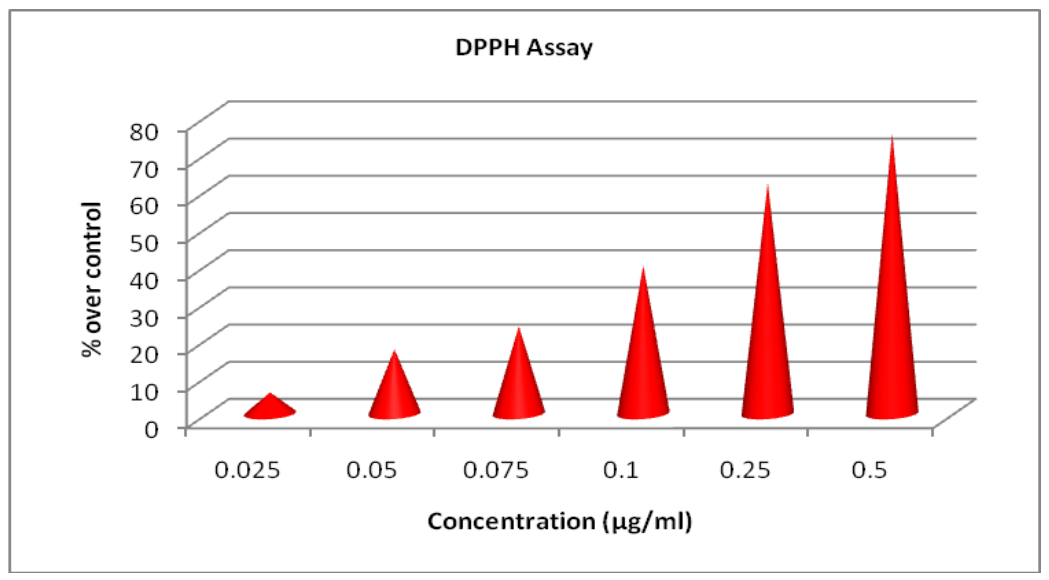

Free Radical Scavenging Activity of the Extract

In order to evaluate the scavenging activities of the plant extracts, parameters like hydrogen peroxide test, superoxide analysis, lipid peroxidation inhibition and DPPH assay were studied. Extract exhibited significant free radical scavenging activity against selected radicals (Figure 1-4). Activity was found to be directly proportional with concentration of the plant extract. Maximum activity was found with the concentration of $0.5 \mu \mathrm{g} / \mathrm{ml}$; whereas no reaction was found with the concentration of less than $0.025 \mu \mathrm{g} / \mathrm{ml}$. Antioxidant property of Cassia alata extract is been majorly complimented by the bioactive components present in the extract such as alkaloids and flavonoids (Sagnia et al., 2014), however phenol mediated free radical scavenging activities also have been reported by Sharma and Vig (2013).

In conclusion Cassia alata leaf extracts was found to be an effective agent for the synthesis of silver nanoparticles. Silver nanoparticles were synthesised in a notable time with impeccable rate. Antioxidant activity of extract found very promising as it could modulate free radical scavenging upto 90\% compared that with the absence of extract. It is assumed that the biotechnological activities of leaf extracts are complimented by its phytocomponents. Phenols, alkaloids and flavonoids constitute major part of extract. The results observed from this study can be taken forward to develop a nanoparticle bound antioxidant with high degree of activity.

\section{References}

Ahmed, S., Ahmad, M., Swami, B.L., Ikram, S. 2014. A review on plants extract mediated synthesis of silver nanoparticles for antimicrobial applications: A green expertise. $J$. Adv. Res., 7: 17-28. doi:10.1016/j.jare.2015.02.007

Aksoy, L., Kolay, E., Aĝilönü, Y., Aslan, Z., Kargioĝlu, M. 2013. Free radical scavenging activity, total phenolic content, total antioxidant status, and total oxidant status of endemic Thermopsis turcica. Saudi J. Biol. Sci. $\quad 20:$ 235-239. doi:10.1016/j.sjbs.2013.02.003

Banerjee, P., Satapathy, M., Mukhopahayay, A., Das, P. 2014. Leaf extract mediated green synthesis of silver nanoparticles from widely available Indian plants: synthesis, characterization, 
property and toxicity analysis. Biores. Bioprocess, 1: $3 . \quad$ doi: 10.1186/s40643-014-0003-y

Bhat, P., Savitri, V., Laxmi, P., Jenitta, E., 2016. A Study on the Phytochemical Analysis, Silver Nanoparticle Synthesis and Antibacterial Activity from Seed Extract of Areca catechu L. Int. J. Biochem. Res. Rev., 9: 1-9. doi:10.9734/IJBCRR/2016/21864

Ćetković, G.S., Čanadanović-Brunet, J.M., Djilas, S.M., Tumbas, V.T., Markov, S.L., Cvetković, D.D. 2007. Antioxidant potential, lipid peroxidation inhibition and antimicrobial activities of satureja montana L. subsp. kitaibelii extracts. Int. J. Mol. Sci., 8: 1013-1027. doi: $10.3390 / 18101013$

Chatterjee, S., Chatterjee, S., Dutta, S. 2012. An Overview on the Ethnophytopathological Studies of Cassia alata - an Important Medicinal Plant and the Effect of VAM on its Growth and Productivity. Int. J. Res. Bot., 2: 13-19.

Gaddam, S.A., Kotakadi, V.S., Sai Gopal, D.V.R., Subba Rao, Y., Varada Reddy, A. 2014. Efficient and robust biofabrication of silver nanoparticles by cassia alata leaf extract and their antimicrobial activity. $J$. Nanostructure Chem., 4: 82. doi:10.1007/s40097-014-0082-5

Hasan, S. 2015. A Review on Nanoparticles: Their Synthesis and Types. Res. J. Recent Sci., 4: 1-4.

Hazra, B., Biswas, S., Mandal, N. 2008. Antioxidant and free radical scavenging activity of Spondias pinnata. BMC Complement. Altern. Med., 8: 63. doi:10.1186/1472-68828-63

Krithiga, N., Rajalakshmi, A., Jayachitra, A. 2015. Green Synthesis of Silver Nanoparticles Using Leaf Extracts of
Clitoria ternatea and Solanum nigrum and Study of Its Antibacterial Effect against Common Nosocomial Pathogens 2015.

Lu, J.J., Dang, Y.Y., Huang, M., Xu, W.S., Chen, X.P., Wang, Y.T., 2012. Anticancer properties of terpenoids isolated from Rhizoma Curcumae - A review. J. Ethnopharmacol. 143, 406411. doi:10.1016/j.jep.2012.07.009

Mahmood, A.M and Doughari, J.H, 2014. Phytochemical screening and antibacterial evaluation of the leaf and root extracts of Cassia alata Linn $2,124-129$.

Many, J.N., Radhika, B., 2014. Issn 22773851 Synthesis of Silver Nanoparticle Using Fresh Tomato 4, 12-15.

Meenupriya, J., Vinisha, A.S., Priya, P., 2014. Cassia alata and Cassia auriculata - Review of their bioactive potential. World J. Pharm. Sci. 2, 1760-1769.

Meng, Q., Qian, Z., Li, X., Li, D., 2012. Free radical scavenging activity of Eagle tea and their flavonoids. Acta Pharm. Sin. B 2, 246-249. doi:10.1016/j.apsb.2012.02.012

Mir, M.A., Sawhney, S.S., Jassal, M.M.S., 2013. Qualitative and quantitative analysis of phytochemicals of Taraxacum officinale. Wucpecker J. Pharm. Pharmacol. 2, 1-5.

Mohideen, S., Sasikala, E., Aj, P.A., 2005. Pharmacognosy of Cassia Alata Linn - leaves 4-9.

Ogunwande, I.A., Flamini, G., Cioni, P.L., Omikorede, O., Azeez, R.A., Ayodele, A.A., Kamil, Y.O., 2010. Aromatic Plants growing in Nigeria: Essential Oil Constituents of Cassia alata (Linn.) Roxb. and Helianthus annuus L. 4, 211-217.

Parekh, J., Jadeja, D., Chanda, S., 2005. Efficacy of Aqueous and Methanol Extracts of Some Medicinal Plants 
for Potential Antibacterial Activity. Methods 29, 203-210.

Patel, K., Gadewar, M., Tripathi, R., Prasad, S.K., Patel, D.K. 2012. A review on medicinal importance, pharmacological activity and bioanalytical aspects of betacarboline alkaloid "Harmine" Asian Pac. J. Trop. Biomed., 2: 660-664. doi:10.1016/S2221-1691(12)60116-6

Roy, A., Sitalakshmi, T., Rv, G., Lakshmi, T., V, V.P. 2011. In Vitro Antioxidant and Free Radical Scavenging Activity of the Ethanolic Extract of Dioscorea villosa (Wild Yam) Tubers, 3: 214-215.

Sagnia, B., Fedeli, D., Casetti, R., Montesano, C., Falcioni, G., Colizzi, V. 2014. Antioxidant and antiinflammatory activities of extracts from Cassia alata, Eleusine indica, Eremomastax speciosa, Carica papaya and Polyscias fulva medicinal plants collected in Cameroon. PLoS One, 9: 1-10. doi:10.1371/journal.pone.0103999.
Senthilkumar, R.P., Malayaman, V., Sindhuja, S. 2013. Phytochemical screening and antibacterial evaluation of the leaf, flower and seed coat extracts of Cassia alata L. J. Chem. Pharm. Res., 5: 740-744.

Sharma, S., Vig, A.P. 2013. Evaluation of in vitro antioxidant properties of methanol and aqueous extracts of Parkinsonia aculeata L. leaves. Sci. World J., doi:10.1155/2013/604865

Sherikar, A.S., Mahanthesh, M.C. 2015. Evaluation of aqueous and methanolic extract of leaves of Epipremnum aureum for radical scavenging activity by DPPH Method, total phenolic content, reducing capacity assay and FRAP assay, 4: 36-40.

Von White, G., Kerscher, P., Brown, R.M., Morella, J.D., McAllister, W., Dean, D., Kitchens, C.L. 2012. Green synthesis of robust, biocompatible silver nanoparticles using garlic extract. J. Nanomater., doi:10.1155/2012/730746.

\section{How to cite this article:}

Kavipriya, K., and Chandran, M. 2016. Analysis of Phyto-Constituents and Free Radical Neutralizing Activity of Cassia alata - A Green Source for Ag Np's Synthesis. Int.J.Curr.Microbiol.App.Sci.5(4): 476-482. doi: http://dx.doi.org/10.20546/ijcmas.2016.504.056 